\title{
A ALTERIDADE A MARGEM DO PENSAMENTO DO NATURALISTA ALEXANDRE RODRIGUES FERREIRA
}

\section{THE ALTERITY THE MARGIN OF THE NATURALIST'S THOUGHT ALEXANDRE RODRIGUES FERREIRA}

\author{
Luciano Sá Ribeiro \\ Rafael Ale Rocha
}

\section{RESUMO}

$\mathrm{Na}$ Amazônia esteve presente o totalitarismo do colonizador, do pesquisador, do naturalista e do especialista que desenvolvem em muitos momentos a classificação, ou seja, a taxonomia. A classificação dentro deste contexto esconde e oculta o outro e diante disso o ser que exige a alteridade entra em conflito com a totalidade. Por isso, o objetivo deste artigo é mostrar como o outro (alter) é apresentado no olhar do viajante. Almeja- se também, com esta breve reflexão, chamar a atenção para a interpretação que é lançada sobre o ser amazônico, para assim promover uma ruptura com as formas de interpretação, classificação e o encobrimento da alteridade na Amazônia colonial. Partindo do método hermenêutico, construiremos uma crítica a localização deste outro dentro da visão do naturalista.

Palavras chave: naturalista; Alteridade; Amazônia colonial;

\begin{abstract}
In the Amazon was present the totalitarianism of the colonizer, the researcher, the naturalist and the specialist who develop in many moments the classification, that is, the taxonomy. Classification within this context conceals and hides the other, and the being that demands alterity comes into conflict with the totality. Hence, the purpose of this article is to show how the other (alter) is presented in the look of the traveler. It is also hoped, with this brief reflection, to call attention to the interpretation that is launched on the Amazonian being, in order to promote a rupture with the forms of interpretation, classification and the cover - up of alterity in the colonial Amazon. Starting from the hermeneutic method, we will construct a critique of the location of this other within the naturalist's view.
\end{abstract}

Keywords: naturalist; Otherness; Colonial amazon 


\section{Introdução}

Dentre toda a movimentação existente no século XVIII, destaca-se uma nova forma de observar a realidade. É neste contexto que a ciência se torna a grande luz, ou seja, a razão é a grade motriz deste século. Nele está presente todo o desejo do homem de, com a prática e com o domínio dos métodos científicos, desmistificar todas as formas de conhecimento.

Segundo Raminelli (1997), a Viagem Filosófica foi concebida sob os auspícios da Academia das Ciências de Lisboa, Ministério de Negócios e Domínios Ultramarinos, e planejada pelo naturalista italiano Domenico Vandelli, radicado em Portugal desde o fim do período pombalino.

No final do século XVIII, período de difusão das ideais iluministas, Portugal ao lado de outras metrópoles como a Espanha, a França, a Inglaterra - empenhou-se em incorporar práticas científicas em sua política colonial. No Brasil, ganhou notoriedade a expedição liderada por Alexandre Rodrigues Ferreira, naturalista brasileiro formado na Universidade de Coimbra que explorou a região amazônica de 1783 a 1792. Criam-se então categorias, que segundo os pensadores da revolução iluminista, serviriam como um método que garantiria que todo e qualquer objeto de estudo fosse analisado por um processo empírico matemático. Este processo, caracterizado pelo mecanicismo herdado de Descarte, observava, por meio do olhar do cientista, para todas as coisas como sendo uma grande máquina que precisava ser estudada.

O homem passa a ser estudado como máquina e os povos são estudados de forma mecânica sem a preocupação com quem ele de fato é. O autóctone é então visto como uma engrenagem da grande máquina que é a natureza exuberante. O ser destas narrativas e intepretações é o ser do colonizador e do narrador que luta e que visa sua permanência, o manter-se sendo. Esta luta onde todos visam preservar e ampliar seu espaço se converte em conflito e limitação recíproca. Nela a paz é instável, não resiste à luta dos interesses. Em sua busca de manter-se sendo, o ser se caracteriza pela totalização que consiste em transformar o outro no mesmo, tal qual se dá com o alimento incorporado ao organismo. A totalização preserva o ser, o sujeito, o ser do dominador pela negação da alteridade. Ao fugir da totalização instrumental, o outro se revela como exterioridade, como aquele que é livre, isto é, ele não é parte do meu mundo.

A valorização da questão do outro, da alteridade é reconsiderar a posição do sujeito na relação. A questão da alteridade busca tornar visível o outro que não aparece, pois natural é o 
contexto encobridor, uma vez que os nativos da região não são o centro dos estudos e observações das viagens. As viagens tinham o objetivo de criar nos acervos, nos inventários das riquezas pertencentes a colônia, a colônia que era o lugar de extração de riquezas para à coroa.

O valor da informação etnológica existente nos textos de Alexandre Rodrigues é de grande importância. Mas desigual às vezes. Nos muitos relatos quase não se retrata o que era de fato a vida dos povos. Sempre se diz somente das suas práticas culturais que por sinal passam a serem então inaceitáveis. Alguns naturalistas sempre teceram uma serie de comentários e muitos deles cheio informações desencontradas, por muitos motivos; as vezes por possuir um olhar fechado ao novo e carregado de prenoções, pré-conceitos, por valores e princípios morais do seu tempo, da sua própria formação humana e claro da sua formação intelectual.

\section{O outro no olhar do Viajante}

As observações das sociedades indígenas da América, como nos firma Renan Freitas Pinto, e de outras regiões, foram usadas para explicar o sistema em que o homem é parte da história natural utilizada por Buffon e Alexandre Rodrigues. É a partir da ideia de que o homem é parte da história natural que ele descreve e define os índios da região amazônica.

No diário da Viagem, há um detalhamento das características dos animais onde os autóctones também estão incluídos. Faz-se de tudo aquilo que é visto uma longa análise com o intuito de se chegar ao conjunto de informações que são adquiridos sobretudo dos animais, das plantas e dos nativos, por meio de estudos anatômicos que parecem destacar, ou melhor, comprovar a inferioridade dos seres vivos das Américas.

O outro a que nos referimos são os nativos, que eram vistos como sendo parte da diversidade existente nestas terras. Alexandre Rodrigues ao referir-se a uma aldeia de índios atacada por outros três grupos indígenas; os Manaós, Xapuenas e Martiuenas, ele se fere aos que foram acatados como os domesticados ${ }^{9}$. Esta categoria utilizada por ele mostra que em sua concepção os nativos viviam em estado bruto e selvagem, que precisavam ser modelados e só começavam a possuir valores quando conviviam com o branco.

${ }^{9}$ (...) tornar doméstico; adaptar (animal ou planta) à vida em associação com seres humanos. Amansar ou adestrar (animal selvagem); domar. (FERREIRA. 2010, p. 264) 
O olhar do viajante também se volta para a dimensão religiosa. Segundo ele "enquanto à religião, criam com uma espécie de maniqueísmo, que havia dos deuses um chamado Mauari, autor de todo o bem, outro por nome Sarauá, autor de todo o mal" (FERREIRA, s/d, p 615). Conforme Alexandre Rodrigues:

É certo que alguns, que entre os diversos princípios da religião, que alguns d'elles professam, um d'elles é o de sustentarem, que ha deuses autores dos males, que affligem a espécie humana. A estes representam os gentios debaixo de formas as mais horrendas; e todo o culto que lhes dam, o dirigem ao fim de applacarem a cólera d'estas terríveis divindades. Crêm como os antropomorphitas, que os seus deuses tem fórma humana; porem com uma natureza superior á do homem; e sobre as qualidades e operações d'estes deuses, imaginam fabulas as mais absurdas e incoerentes que se pose imaginar. (FERREIRA, s/d, p 619)

O pensamento interpretativo que envolve o nativo diante desta pratica é a ideia de infantilismo, pois tais práticas religiosas e cotidianas são vistas como incomuns e anormais. Suas formas de crenças não são compreendidas pelo naturalista, pois não se pensava que em todas as culturas se tem representações das divindades, mas o que parece é que a única forma de representação da divindade é a monoteísta ou o modelo Iluminista. Muitos traços das crenças existentes entre os povos foram nulificados por força da dominação e imposição de uma nova forma de expressão cultura religiosa: ritos, símbolos, imagens e a própria ideia de evolução racional. Todorov fala em seu livro; a conquista da América: a questão do outro, o que foi feito pelos espanhóis; a substituição dos símbolos dos templos, imagens de santos católicos colocados nos lugares de adoração dos nativos, sacerdotes nativos substituídos por sacerdotes cristão, rituais nativos substituídos por rituais cristãos.

"Os índios foram concebidos como trabalhadores agrícolas e denunciados pela inércia, preguiça e resistência ao "mundo civilizado". Os ritos e mitos indígenas não despertaram a curiosidade do naturalista. As memórias sobre os índios da Amazônia destacam as vestimentas, armas de guerra, utensílios de barro, confecção de canoas e moradias, sem se preocuparem com as canções, cerimônias e histórias narradas pelas diversas etnias da região. Quando comparadas às descrições quinhentistas, as memórias de Ferreira são simplórias, destituídas de profundidade, contendo análises apenas superficiais sobre o cotidiano e comportamento dos índios da Amazônia. O naturalista não recorreu ao tempo, quase dez anos, em que conviveu junto às diversas comunidades para escrever as memórias dedicadas aos índios". (RAMINELLI, 1997, p.9)

A Viagem Filosófica formula-se como um projeto, no âmbito dominante do interesse e da política oficial em relação ao Amazonas. Pela própria intenção da viagem, o empenho maior estava em construir conhecimentos sobre as áreas de interesse. Os costumes estão fora 
da linha de observação do naturalista, pois até mesmo as intenções da viagem não permitiam, os hábitos e costumes não foram estudados, foram vistos somente por uma análise periférica realizada pelo naturalista. Devemos então pensar nas muitas formas de expressões dos grupos viventes dentro da Amazônia e seus costumes, sobretudo, os costumes da guerra que Alexandre Rodrigues define como ímpio o comportamento de quase todos os gentios pela ocasião da guerra.

Quando paramos para observar, ao longo da história da humanidade, veremos as inúmeras batalhas que se fizeram no seio das grandes civilizações. Ao falar das batalhas e das guerras que faziam aos nativos não podemos nos esquecer do significado destas práticas, uma vez que não guerreavam só pelo simples prazer de guerrear. A guerra tinha uma grande importância. Para muitas nações nativas a guerra era fundamental. Ela dava sentido à vida em sociedade e não acontecia só por questões políticas ou econômicas, mas ainda pela reprodução de valores sociais. É importante lembrar que a guerra fazia parte da preparação do guerreiro. Não havendo guerra, não havia como formar guerreiros ou como testar sua bravura, que faz parte dos valões que compõem a autoestima da sociedade (BENTES, 2007, p. 32 )

Segundo Bentes (2007), a guerra para alguns povos nativos possui importância cultural. As guerras extrapolavam os limites do mundo físico e servia também como instrumentos de respeito e preservação da memória e como mecanismo de realinhamento entre o mundo dos espíritos e das sociedades nativas. Por isso, faziam guerra por muitos motivos; para conquista de terras mais férteis e regiões de floresta onde a caça era mais abundante, para espantar os maus espíritos, para lembrar pessoas da família mortas, para vingar. "Os Tupinambá não devoravam seus inimigos por piedade, mas por vingança e honra" (CASTRO, 1992, p.45), e para mostrar que eram fortes. "A guerra era decidida pelo conselho tribal” (BENTES, 2007, p. 33). A prática da antropofagia, que muito acontecia no contexto citado anteriormente, é descrita pelo viajante da seguinte forma;

Estas barbaridades, que elles commettem, durante o furor da guerra, são a que os Uerequena praticam de sangue frio com os prisioneiros, que aplica para o seu sustento, longo tempo logo depois de concluída a guerra. Viram em outro tempo os cabos das nossas tropas, que elles tinham currais de gentios prisioneiros, assim como nos temos de gado para os açougues. D'elles se conta mesmo que de muitas outras nações d'America, que praticam extraordinário costume. (FERREIRA, s/d, p 620)

Alguns fatos eram desconhecidos pelo viajante a respeito da prática de guerra e do pós-guerra. Como já afirmei anteriormente, os que participaram das guerras eram guerreiros. 
Após os violentos combates que eram travados, os que eram aprisionados ficavam dentro das aldeias, eram bem tratados e, em algumas tribos, podiam até se casar passando a integrar a vida da aldeia de seus membros.

Outras tribos, como era caso de alguns troncos do Tupi, tinham hábitos antropofágicos e podiam comer seus prisioneiros de guerras em rituais religiosos. Acreditavam que comendo a carne seriam vingados os parentes mortos e que teriam as melhores qualidades do guerreiro. Se, por exemplo, ele fosse um bom corredor, herdariam a velocidade de suas pernas; e se fosse um bom guerreiro herdariam toda sua bravura.

A violência que acompanhava os atos de "conversão" (os "descimentos", as "tropas de resgate", as "guerras justas") só pode ser minimizada e esquecida porque segue - narrativamente - os relatos sobre a antropofagia, os prisioneiros destinados à morte, os ataques e mortes de colonos [...]. Para ser esquecido o genocídio como uma simples e merecida reação a atos de uma maldade desmedida e inexplicável que legitima a hipótese de uma natureza má daquelas populações autóctones, que assim precisariam ser vencidas e subjugas. (OLIVEIRA, 2016, p.19)

A prática da antropofagia era rara entre os nativos, mas para justificar as ações, ela fora divulgada de modo a entender que este era um ato praticado por todos destas terras. Durante muito tempo as viagens relataram situações em que a margens dos rios mais pareciam com açougues, no texto de Alexandre Rodrigues mais uma vez esta ideia aparece. Esta ideia que se reproduz ao longo da história que uma vez nestas terras teriam grandes chances de ser devorados pelos seus moradores, mas na verdade prática da antropofagia não acontecia pelo simples prazer em comer carne humana como se fazia entender.

Em Alexandre Ferreira se repetem os preconceitos, que já haviam sido praticados por La Condamine e Buffon. O naturalista faz um relato visual e as vezes com preconceito. Por exemplo, quando ele fala dos Cambébas, dos Uerequena e os Muras ele faz um relato visual. Isto no ano de 1787, vejamos:

Os antigos Cambébas, como eu já escreve na memória a que elles deram assumpto, datada em 17 de setembro do referido anno, imprensavam entre as duas talas as cabeças das crianças, para se fazerem chatas, outras lhes davam uma figura conica, outros quadrada. O Uerequena, como deixo escripto na memória de 29 de Agosto, rasga, e distende as estremidades das orelhas. O Mura, como também escreve na memória de 30 do mesmo mez, e outros muito gentios furam ambos os lábios, e trazem introduzidos nos furos ou os batoques, os quaes parecem marcas de coquilho [...] (FERREIRA, s/d, p. 622) 
Sendo que para alguns os Cambebas eram os mais "civilizados", estas informações que são passadas pelo viajante a respeito dos nativos só vinham a reforçar uma visão preconceituosa, pois estas práticas são vistas como hábitos estanhos, que nascem não só em torno da Amazônia, mas de toda a América do Sul, ou seja, selvagens por suas práticas e hábitos. Fala-se também da nudez na qual eles se encontravam e de uma indolência que os convida a poupar-se a todo e qualquer tipo de trabalho. Nascem assim, estereótipos; o preguiçoso, indolente, pouca capacidade racional.

Dentro dos relatos, os nativos parecem perderem-se na grandiosidade da floresta, o que afirma o nativo como parte da natureza dentro de uma visão do naturalista. Nesta visão sempre se tem a impressão de que o homem sempre é visto como o invasor e que precisa retira-se.

\section{$O$ ser que exige a alteridade}

Damos continuidade, mas agora se faz necessário olhar para o ser que exige a alteridade. Emmauel Lévinas (1906-1995) constrói uma visão do outro, a visão que estabelece o indivíduo não como determinação de fatores externos, mas por determinação de seus próprios fatores. Este ser que exige a alteridade entra em conflito contra a totalidade, que mostra dentro do quadro das estruturas que fundamentam o etnocentrismo, pois segundo Lévinas o ser confunde as suas particularidades com a totalidade. Em toda a história das Américas e da Amazônia esteve presente o totalitarismo do "colonizador", do "pesquisador", do "naturalista" e do "especialista".

A conquista é o grande propósito de toda totalidade, é uma busca por hegemonia e soberania levando o ser que de fato existe plenamente com todos os direitos, que se torne um anônimo sem nenhuma consciência de si mesmo. Há uma mutilação muito acentuada, que provoca muito visivelmente a deformação deste Ser fazendo o uso da força destruindo até o mais profundo. Segundo Dussel: “o "eu conquisto" é práxis, mas práxis da opressão, da morte, do extermínio, da negação” (DUSSEL apud ZIMMERMAM, 1987, p.148)

Percebemos que a "totalidade ontológica" 10 sempre precisou ser mantida para garantir que jamais o sujeito viesse a construir, partindo de si mesmo, as condições para definir sua

10 Totalidade ontológica oprimi o outro, o reduz a uma mera exterioridade a um ente do próprio mundo. O autóctone não tem lugar, não tem vez porque dentro da estrutura não há espaço para a realidade que ele é 
própria identidade quanto sujeito. A alteridade é uma busca única e verdadeira pelo ser desaparecido, pelo ser inconsciente. É um desejo de começar observando o grito do oprimido sendo assim bem diferente da totalidade que não se admite a diversidade, mas "um só rei, uma só religião, um só império [...]” (ZIMMERMAM, 1987, p.180)

Quando falamos da alteridade nos referimos ao outro, que exige ser visto como tal. Em toda a história da dominação do continente americano, e da Amazônia o sujeito tem sido visto único e exclusivamente a partir das muitas representações formuladas pelos "conquistadores', ou melhor, "invasores". Apesar de existirem posteriormente cartas e fontes primarias elaboradas pelos povos na américa, não chegaram a ser conhecidas ou não foram consideradas. Tzvetan Todorov (1986), fala a respeito das fontes que muitas vezes podem ter recebido e influencias externas em suas narrativas ou tenham sido mudadas por interesses do colonizador, do cronista. Sobre a interpretação dos índios é interessante ainda o que diz Todorov, ou seja, colombo invés de interessar-se pelo que a realidade ia apresentar como novo, ele se limita a interpretá-la com ideias preconcebidas. (TODOROV, 1983, p. 258).

Em uma das primeiras imagens narrativas aparecem homens e mulheres nus de muita beleza, ora como gente "bestial" seres em estado de selvageria, ora aparecem dentro da imagem edênica, ou seja, dentro de um referencial semítico mitológico, ora como o "bom selvagem", definição, imagem destacada por Russeau, Las Casas, o francês Montaigne e antes dele os poetas também franceses Étienme Jodelle ${ }^{11}$ e Pierre de Ronsard ${ }^{12}$ também elogiavam o estado natural dos povos americanos.

Para muitos na Europa os índios eram intelectualmente e moralmente inferiores aos europeus. Esta classificação, estas características são reforçadas no instituto de justificar os atos realizados contra este outro, este ser. Com isso, desenvolvendo uma anulação do ser e da sua própria identidade.

Levantamos os questionamentos a respeito do lugar do ser dentro do espaço que é comprimido pelas muitas formas de negação do sujeito, que se apresenta no contexto da América Latina e também na Amazônia. O novo mundo ${ }^{13}$, muito antes de ser explorado, sofre

${ }^{11}$ Étienme Jodelle (1532? -1573) escreveu uma Ode, onde exalta a figura o selvagem livre e nu em oposição ao civilizado hipócrita.

${ }_{12}$ Pierre de Ronsard (1524- 1585) fez o elogio da vida simples do indígena brasileiro

13 Novo mundo no sentido de ser jovem e imaturo, menos evoluído. O velho mundo aquele que domina o ferro, domina as técnicas, é o civilizado. Neste sentido é que se definiu esta afirmação. 
sua primeira intervenção histórica que pode ser percebido pelo tratado de Tordesilhas (1494), a América portuguesa e a espanhola. Os europeus fazem uma divisão dos territórios desconhecidos. O ser que está dento do novo mundo não é levado em consideração, pois as disputas de reis com outras nações por definição de territórios e as intervenções militares sobre o espaço e os povos amazônicos, teve como consequência a violência sofrida por meio da dominação e conquista, cujo os instrumentos eram as armas da coroa e da própria Igreja.

O ser luta por seu espaço, pois muitas vezes o dasein (o ser aî), como afirma Lévinas, pode estar tirando o lugar de alguém. Podemos intuir que o ser amazônico, o seu lugar como o outro (alter), foi tirado quando o ser dominante justificou seu ser sobre o ser que era totalmente outro - o amazônico.

A classificação do ser em sua subjetividade, não pode ser classificada por uma nominação externa, pois só o próprio ser pode se autodefinir. O estado de escravidão em que os autóctones eram tratados, em uma total negação do seu ser pela usurpação da liberdade. Neste sentido, Grünberg afirma:

A servidão frente aos brancos apenas os permite cultivar suas próprias plantações e a febre e as enfermidades da civilização acabam com eles. É triste a sorte desta pobre gente morena que esta sucumbindo às duvidosas benesses da chamada "cultura moderna. (GRÜNBERG apud RENAM FREITAS, 2006, p 209)

Nestes relatos percebemos que a escravidão é uma constante nesta região, pois os nativos eram pegos e levados, postos em currais, onde eram tratados como animais. $\mathrm{O}$ que era alimentado como informações sobre os autóctones era um conjunto de dados, onde muitos consistiam em frutos da imaginação dos cronistas que desejando que suas histórias não fossem esquecidas, fantasiavam, com isso alterando de fato o que seria o verdadeiro rosto de povos que viveram e que vivem nesta região. Contudo, nem todos os cronistas agiam desta forma, alguns (ainda que raros) faziam relatos e ensaios etnográficos. A identidade deste povo se choca com a cultura moderna, que na visão dos dominadores seria a melhor desenvolvida (salvo o caso que em alguns momentos a forma de vida do nativo é admirada e elogios são traçados as sociedades indígenas), só garantia a anulação dos indivíduos revelando que a tentativa de impor uma cultura a outra é desastrosa pela forma em que afeta toda a ordem e a configuração dos indivíduos dentro da realidade à qual pertencem. 
Muitos índios possuíam status de livre. Todavia, essa política da liberdade indígena mais do que o caráter "humanitário" implícito na defesa da liberdade dos índios, o que estava em jogo era a reestruturação econômica da região e a diminuição do poder político e econômico dos religiosos, vistos como obstáculo para a prosperidade dos colonos, o bem comum e a opulência do Estado

O não reconhecimento da alteridade destes povos, era no plano político da colonização, pois mesmo com a política de libertação de alguns nativos, o que estava por traz era uma política de dominação ideológica por meio dos parâmetros da civilização, ou seja, a civilização é a expressão da "autoimagem da classe alta europeia em comparação com outros, que seus membros consideravam mais simples ou mais primitivos [...]” (ELIAS, 1994, p.54). O conceito de civilização é a forma como a alta classe europeia entende o desenvolvimento da sua própria história, estabelecendo uma relação de distanciamento entre o "nós" - civilizados e o "eles" - bárbaros. Assim, as nações que se denominam civilizadas acreditam estar no ápice do desenvolvimento da humanidade, o que lhes dá o direito de subjugar aqueles que são anteriores à civilização (Ibid., p.64)

Essa política não via índio como outro, com seus modos próprios de organização social, cultural a necessidade de submetê-los culturalmente como índios vencidos e totalmente integrado dentro dos parâmetro e padrões civilização europeia. As razões da expropriação de suas terras e de utilizá-los como escravo impôs ao colonizador as necessidades de generalizálos às condições de domínio e manutenção das estruturas coloniais. Nos relatos de Alexandre Rodrigues aparecem os nativos contabilizados como mercadorias, eles tinham uma única função, que era produzir para gerar lucros para a coroa.

O ser, para alcançar o seu dever-ser, precisa lutar contra todo o solipsismo que se instalou nas profundezas da consciência do ser ocidental. Queremos a partir da ontologia destacar (mesmo que os índios, conforme historiografia mais recente, tenham feito parte da sociedade colonial e terem atuado intensamente na construção da mesma) que o ser que exige alteridade quer afirmar que também possui direitos, quer dizer que também pensa e possuir vontade própria, não mais admite ser manipulado pelos conjuntos de interesses que tentam, com todas as forças, tornar cada vez incompreendida sua forma de ser. A classificação tem produzido o esquecimento dos sujeitos, às vezes não se é capaz de localizar sua própria identidade. 


\section{A classificação como negação da Alteridade}

A classificação tem como condição primeira para sua prática a atribuição de categorias, divisões e intitulação dos seres, dos objetos. Na taxonomia que é realizada dos povos da Amazônia neste período está presente uma carga considerável de preconceitos, e com base nestas prenoções, eles são classificados como "débeis de menor porte. Essa ideia de que os animais, as plantas e os próprios homens da América eram menos vigorosos que os seus semelhantes da Europa, tinha uma aceitação generalizada”. (RENAM FREITAS, 2006.p $158)$.

Muitos prensadores e viajantes que estiveram por esta região teceram seus comentários e impressões a este respeito. Muitos pensadores da tradição intelectual teceram pensamentos sobre a gente deste lugar que justificam, como por exemplo: a escravidão, afirmam que há "países em que o calor enerva o corpo e enfraquece tanto a coragem, [...] os homens efetuam um dever penoso por temor do castigo: a escravatura, portanto, choca menos a razão [...].” (MONTESQUIEU apud GONDIM. 1994. p 75). Muito se utilizou destes pensamentos eruditos que possuíam toda uma construção histórica. Montesquieu traz consigo elementos da servidão natural de Aristóteles.

Estas justificativas, como esta mencionada, foram utilizadas pelos exploradores, pois por serem preguiçosos, inferiores poderiam ser escravizados, serem manipulados como uma mercadoria. Contra eles, os invasores, empreitavam guerras, onde muitos eram presos como animais. Sobre isso Cristóbal de Acuña, um século antes de Alexandre Rodrigues afirma:

Ordenaram-lhes os portugueses que entregassem todas as flechas envenenadas [...] E, vendo-os tão desarmados, os portugueses tomara grande quantidade deles e encerraram-nos em um curral forte com suficiente guarda [...] Em breve espaço de tempo saquearam toda a aldeia [...] ( ACUÑA, 1994.p.185 )

Os autóctones e suas relações, sempre aparecem como o dominado frente ao dominador, que se impõe sobre dura pena de conduzir cada vez mais suas identidades a uma total anulação como outro. Muitos nomes são atribuídos, mas podermos perceber que nenhum deles quer mostrar, ou pelo menos tentar desvelar a face do outro que se torna cada vez mais escondida. Todas as vezes que se atribui para o outro uma característica que é fruto de uma nomeação que parte do externo para interno, sempre será uma imposição de características, de formas e modelos. 
Acontece através da classificação a transferência de modelos quando se monta através da estrutura única e inquestionável do outro a aplicação de elementos já existentes em realidade diferentes que parecem abarcar a realidade que se apresenta, mas quando na verdade não são capazes de gerar a compreensão necessária do outro.

A similitude ou semelhança significarão a placidez da permanência do mundo familiar. O novo é filtrado pelo antigo, assegurando a este sua supremacia. A prática de comparar as novidades vistas pela primeira vez com algo pretensamente conhecido, sendo domesticado, fortalecerá e documentará a estabilidade do antigo. (GONDIM, 1994 p.38)

As semelhanças são também mecanismos de negação do outro. Com isso queremos dizer que toda a ação comparativa não deixa de ser uma negação do outro. Um ponto que devemos salientar é que em relação aos europeus, os nativos eram extremamente incapazes e não possuíam nenhum vigor físico, isso porque o modelo ideal era o homem europeu. Os que não possuíam semelhanças com o homem do ocidente eram considerados inferiores. Muitas observações construíam-se com base nas informações e dados que chegavam aos escritórios dos colecionadores. Muitas das reflexões que apareciam eram elaboradas sem os seus mentores nunca terem chegado perto destas terras.

As viagens dos naturalistas e de muitos outros que passaram por essa região eram um relato da natureza, uma vez que os interesses econômicos movimentavam cada vez mais as missões de exploração dos novos territórios. Neste contexto não só aterra é saqueada, mas os seus próprios moradores que estavam por séculos nestes lugares passaram a ser tratados como invasores, ou seja, o explorado (tona-se invasor) e o explorador (torna-se o dono) os papéis ficam invertidos. Quando falamos do roubo do qual os nativos são vítimas, queremos falar do roubo da identidade cultural, do roubo dos direitos e costumes e por fim o roubo da liberdade, onde o outro como totalmente outro, é simplesmente uma "extensão" do conquistador e da natureza.

\section{Considerações finais}

A contribuição do Alexandre Rodrigues Ferreira é muito importante para se conhecer o mundo amazônico do período da sua Viagem. As informações que Ferreira traz são diversas e bastantes vastas. Contudo, o naturalista não deixa de repetir modelos interpretativos que são comuns a seu tempo e ao método científico se desdobre para favorecer os interesses econômicos. 
Não podemos negar que existe uma construção de pensamentos que luta para reforçar as muitas ideias distorcidas sobre a Amazônia. O que predomina é a visão do exótico, tudo parece estar ainda numa infância primitiva de povos pacatos e sujeitos a qualquer manipulação. O terreno da classificação é muito vasto e, sobretudo quando realizada na Amazônia, ela continua sendo realizada e exercida pelas muitas estruturas bem montadas que insistem em definir o que não deve ser definido por imposições externas categorizando o outro estigmaticamente.

A alteridade sempre esteve nos relatos e trabalhos realizados em segundo lugar. As riquezas naturais, os rios, as florestas, os animais sempre estão em evidência. A face desde ser que aqui está se tona oculta. Este homem não conhece o seu rosto e muito menos é capaz de si reconhecer. Se olharmos para o atual momento veremos que isso é motivado por séculos de imposição que só tem provocado o abandono do que é de fato parte da sua própria história.

A classificação, ou taxonomia garante o esquecimento da própria identidade dos sujeitos, determinando assim o que e como deve ser. $\mathrm{O}$ ato de classificar impõe maneiras que devem ser aceitas, pois elas traçam paradigmas que devem ser aceitos e tidos como verdades, independente do contexto ou da realidade.

Enfim, queremos então mudar estas muitas ideias e concepções que se constituíram verdade. Fazer com que toda a ideia de inferioridade montada seja destruída por uma nova proposta que garanta a valorização por meio da classificação é um exercício árduo. Pensa-se em uma nova de classificação que deve acontecer de forma inversa da praticada, ela deve acontecer não mais do externo para o interno, mas do interno para o externo, isto é, o outro si autodefinindo, o outro deve dizer de si mesmo o que ele pensa, sente e necessita.

\section{Referências}

ACUÑA, Cristóbal de. Novo Descobrimento do Rio Amazonas. Ed. Trad. e Int. de Antônio R. Esteves. Brasília, Emb. da Espanha, 1994.

BENTES, Dorinethe dos Santos. As primeiras imagens da Amazônia. Manaus: Governo do Estado do Amazonas; Secretária do Estado da Cultura; CCPA, 2007. (Coleção Cadernos da Amazônia) 
CASTRO, Eduardo Viveiros de. O mármore e a murta: sobre a inconstância da alma selvagem. Revista de Antropologia., São Paulo, v. 35, p. 21-74, 04 nov. 1992. Disponível em: <http://www.revistas.usp.br/ra/article/view/111318/109542>. Acesso em: 27 abr. 2019.

ELIAS, Norbert. O Processo civilizador: Uma história dos costumes, trad. Ruy Jungmann, revisão e apresentação Renato J. Ribeiro, Rio de Janeiro: Jorge Zahar, 1994

FERREIRA, Alexandre Rodrigues. Viagem Filosófica ao Rio Negro. Pará: promoção museu paraense Emílio Goeldi. s/d.

FERREIRA, Aurélio Buarque de Holanda. Domesticar. In: DICCIONARIO da língua portuguesa, Curitiba: Positivo, 2010. p. 264

GONDIM, Neide. A invenção da Amazônia. São Paulo: Marco Zero, 1994.

LÉVINAS, E. Entre nós: ensaios sobre a alteridade, $2^{\circ}$ ed. Petrópolis-RJ: Vozes, 2005.

OLIVEIRA, João Pacheco de. A fronteira como guerra permanente e negação de direitos In: O nascimento do Brasil e outros ensaios: "pacificação", regime tutelar e formação de alteridades. Rio de Janeiro: Contra Capa, 2016. p.19.

RENAM FREITAS, Pinto. Viagem das ideias. Manaus. Editora Valer / prefeitura de Manaus; 2006

RAMINELLI, Ronald. Ciência e colonização: Viagem Filosófica de Alexandre Rodrigues Ferreira. 1997. Disponível em: <http://www.historia.uff.br/tempo/artigos_livres/artg610.pdf>.Acesso em: 27 abr. 2019.

TODOROV, Tzvetan v, A conquista da América: a questão do outro, São Paulo, Martins Fontes, 1983, 258p

ZIMMERMAM, Roque. América Latina: O Não Ser, uma abordagem filosófica a partir de Enrique Dussel (1962-1976). São Paulo: Vozes, 1987, p. 185. 